\title{
A Case of Posterior Reversible Encephalopathy Syndrome (PRES) with Chronic Renal Failure
}

\author{
Ibrahim Guney ${ }^{1 *}$, Vefa Oner ${ }^{2}$, Lutfullah Altintepe ${ }^{1}$, Ali Karagoz ${ }^{1}$ and Raziye Yazici ${ }^{1}$ \\ ${ }^{1}$ Nephrology Department, Konya Research and Training Hospital, Konya, Turkey \\ ${ }^{2}$ Radiology Department, Konya Research and Training Hospital, Konya, Turkey
}

\begin{abstract}
Objective: The posterior reversible encephalopathy syndrome (PRES) is a clinical and radiological entity.

Methods: We present a patient with predialysis CRF and PRES

Patient: A 16-year-old man with predialysis CRF admitted with headache and confusion to emergency clinic. Cranial and diffusion magnetic resonance imaging (MRI) were studied and PRES signs were seen in the bilateral parieto-occipital region.

Results: All PRES signs of the patient improved at the $3^{\text {rd }}$ month.

Conclusion: PRES in the patients with CRF was known as uncommon condition. But PRES should be brought to mind, if there is an uremic and/or hypertensive encephalophathy.
\end{abstract}

Keywords: Hypertension; Posterior reversible encephalopathy syndrome; Renal failure

\section{Introduction}

The posterior reversible encephalopathy syndrome (PRES) is chracterized by headache, seizures, altered mental status and visual disturbances. It is a clinical and radiological entity and typically causes the reversible changes in the posterior circulation system of the brain [1]. The most common causes of PRES are hypertensive encephalopathy, eclampsia-preeclampsia, drug intoxications (immunosuppressive and cytotoxic drugs) and chronic renal failure (CRF) with hypertension, collogen vascular disease, thrombotic thrombocytopenic purpura, human immunodefficiency virus (HIV) infection, acute intermittent porphyria, and organ transplantation [2-4]. We present a patient with predialysis CRF and PRES.

\section{Case Report}

A 16-year-old man with predialysis CRF admitted with headache, nausea, vomiting, confusion and fatigue to emergency clinic. $\mathrm{He}$ admitted to nephrology clinic for high creatinemia $(4.8 \mathrm{mg} / \mathrm{dl})$ and malign hypertension (blood pressure is $230 / 110 \mathrm{mmHg}$ ). Tonic-clonic Seizures involving his arms and legs were observed. He did not have findings of meningeal irritation. His visual acuity was decreased, he could perceive hand movements. His pupils isochoric, and direct and indirect light reflexes were normal. Motor and sensory examinations were normal. Deep tendon reflexes were equal and normoactive bilaterally, and Babinski sign was absent bilaterally.

His laboratory tests on admission were as follows: hemoglobin, 12 g/dl; white blood cells, $11.2 \mathrm{~K} / \mu \mathrm{L}$; platelets, $155 \mathrm{~K} / \mu \mathrm{L}$; urea, $133 \mathrm{mg} /$ dl; creatinine $4.8 \mathrm{mg} / \mathrm{dl} ; \mathrm{Na}, 135 \mathrm{meq} / \mathrm{L} ; \mathrm{K}, 6.8 \mathrm{meq} / \mathrm{L} ; \mathrm{Ca}, 8.2 \mathrm{mg} / \mathrm{dl}$; albumin, $3.5 \mathrm{mg} / \mathrm{dl}$; SGOT, $12 \mathrm{U} / \mathrm{L}$; SGPT, $11 \mathrm{U} / \mathrm{L}$;

Cranial and diffusion magnetic resonance imaging (MRI) were studied and PRES signs (hyperintense lesions were observed on T2A and FLAIR sequence) were seen in the bilateral parieto-occipital region (Figure 1). After the anti-hypertensive, anti-edema and anti-epileptic treatments, all signs of the patient improved at the $3^{\text {rd }}$ day. In addition, all PRES signs of the patient also improved at the $3^{\text {rd }}$ month (Figure 2).

\section{Discussion}

The posterior reversible encephalopathy syndrome (PRES) is chracterized by headache, seizures, altered mental status and visual disturbances. It is a clinical and radiological entity and typically causes the reversible changes in the posterior circulation system of the brain, because the posterior cerebral arterial circulation has a lower level of sympathetic innervation [1].

Two possible mechanism have been proposed in the pathophysiology of PRES. The first is vasospasm due to acutely increased blood pressure: it has been suggested that vasospasm contributes to ischemia and

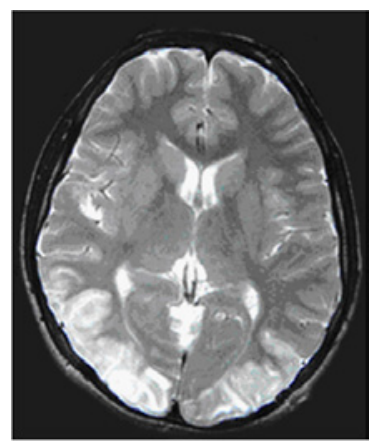

Figure 1: Axial T2 MR image show symmetrically located, bilateral hyper intense lesions in the parietooccipital regions affecting the cortex and sub cortical white matter.

*Corresponding author: Ibrahim Guney, Nephrology Department, Konya Research and Training Hospital, Konya, Turkey, Tel: 0090-3323236709; E-mail driguney@hotmail.com

Received January 19, 2012; Accepted March 23, 2012; Published March 25, 2012

Citation: Guney I, Oner V, Altintepe L, Karagoz A, Yazici R (2012) A Case of Posterior Reversible Encephalopathy Syndrome (PRES) with Chronic Renal Failure. J Nephrol Therapeutic 2:118. doi:10.4172/2161-0959.1000118

Copyright: (c) 2012 Guney I, et al. This is an open-access article distributed under the terms of the Creative Commons Attribution License, which permits unrestricted use, distribution, and reproduction in any medium, provided the original author and source are credited. 


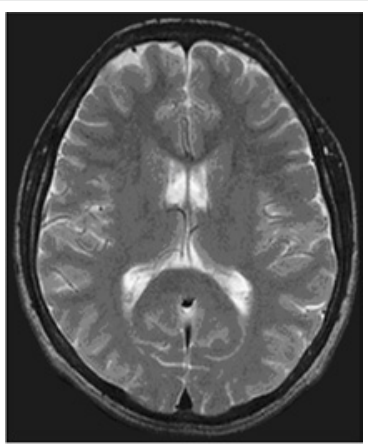

Figure 2: After the treatment ( $3^{\text {rd }}$ month), all of lesions completely disappeared in axial T2 inversion.

cytotoxic edema at regions of the arterial border zone [5]. The second, more recent hypothesis is supported by diffusion images suggesting that dilatation develops in cerebral arterioles due to autoregulatory failure. Cerebral autoregulation keep blood flow constant, and protect the brain during changes in blood pressure; but, sudden and severe increases in blood pressure can impair autoregulation, and this impairment can lead to arteriolar vasodilatation and endothelial dysfunction. In conclusion, plasma and red blood cells migrate to the extravascular space from the intravascular space, and vasogenic edema occurs [6].

The most common causes of PRES are hypertensive encephalopathy, eclampsia-preeclampsia, drug intoxications (immunosuppressive and cytotoxic drugs) and chronic renal failure (CRF) with hypertension, collogen vascular disease, thrombotic thrombocytopenic purpura, human immunodefficiency virus (HIV) infection, acute intermittent porphyria, and organ transplantation [2-4].

PRES can be diagnosed with cranial MR-images. On MR-images, bilateral symmetrical edema in the parieto-occipital region, supplied by the posterior cerebral circulation, is hyperintense on T2-weighted and fluid-attenuated inversion recovery (FLAIR) sequences, and hypointense on T1-weighted sequences [4].

In the treatment of PRES, regulation of blood pressure and seizures are important. Mean arterial pressure should be reduced $20-25 \%$ within the first 1-2 hours. Rapid decrease in blood pressure should be avoided due to the risk of hypoperfusion and consequent cerebral infarction.

PRES mostly is a benign and reversible condition, especially when the causative factor like hypertension can be eliminated. Although PRES can be diagnosed with MR-images, suspicion must be raised by the clinician. Both should be familiar with this underdiagnosed, clinically frightening syndrome to avoid persistent deficits.

As a conclusion, PRES in the patients with CRF was known as uncommon condition. But PRES should be brought to mind, if there is an uremic and/or hypertensive encephalophathy.

\section{References}

1. Hınchey J, Chaves C, Appignani B, Breen J, Pao L, et al. (1996) A reversible posterior leukoencephalopathy syndrome. N Engl J Med 334: 494-500.

2. Garg RK (2001) Posterior leukoencephalopathy syndrome. Postgrad Med $J$ 77: $24-28$

3. Gokce M, Dogan E, Nacitarhan S, Demirpolat G (2006) Posterior reversible encephalopathy syndrome caused by hypertensive encephalopathy and acute uremia. Neurocrit Care 4: 133-136.

4. Ergün T, Lakadamyali H, Yilmaz A (2008) Recurrent posterior reversible encephalopathy syndrome in a hypertensive patient with end-stage renal disease. Diagn Interv Radiol 14: 182-185.

5. Naidu K, Moodley J, Corr P, Hoffmann M (1997) Single photon emission and cerebral computerised tomographic scan and transcranial doppler sonographic findings in eclampsia. Br J Obstet Gynaecol 104: 1165-1172.

6. Vaughan CJ, Delanty N (2000) Hypertensive emergencies. Lancet 356: 411 417 